\title{
Studies of Sulfobromophthalein Sodium (BSP) Metabolism in Man. III. Demonstration of a Transport Maximum (Tm) for Biliary Excretion of BSP *
}

\author{
Leslie J. Schoenfield, Douglas B. McGill, and William T. Foulk \\ (From the Section of Medicine and the Gastrointestinal Research Unit, Mayo Clinic and Mayo \\ Foundation, Rochester, Minn.)
}

Convincing direct evidence that in dogs the secretion of BSP into bile is limited by a maximal rate, similar to the transport maximum $(\mathrm{Tm})$ for certain substances secreted by the renal tubules, has been provided by Wheeler and co-workers (1, 2). They also showed that the Tm for BSP may be estimated from observations on peripheral plasma concentrations during different rates of constant infusion without resort to bile collections, hepatic venous sampling, or measurement of hepatic blood flow. The colorimetrically determined maximal output of BSP in dog bile was equal, on the average, to $87.5 \%$ of the estimated $\mathrm{Tm}$. The existence of a rate-limited BSP transport mechanism in man was inferred from the achievement of a state in which the hepatic removal rate was independent of the absolute plasma concentration and related only to the rate of change of plasma concentration. Utilizing the constant-infusion technic, estimations of $\mathrm{Tm}$ in man, analogous to those in the dog, have been reported by Wheeler and his group and by workers in other laboratories as well $(3,4)$.

The experiments reported herein were performed on a person with complete obstruction of the distal common bile duct due to cancer of the pancreas; a T-tube had been placed in his bile duct without an attempt to remove the obstructing lesion. This circumstance provided an opportunity to obtain evidence supporting the concept of a transport maximum for biliary excretion of BSP in man, even though there was mild (presumably secondary) hepatic damage.

* Submitted for publication December 23, 1963; accepted February 27, 1964.

This investigation was supported in part by research grant AM-06908 from the National Institutes of Health.

\section{Methods}

A 66-year-old white man had been in good health until September 1962, when diarrhea developed. One week after the onset of diarrhea the stools became lighter in color, the urine was dark, and the sclerae yellow. The patient was hospitalized in his home town on September 9. He had no history of abdominal pain, indigestion, fever, or previous jaundice. On September 19 abdominal exploration revealed obstruction of the common bile duct. On biopsy the pancreas appeared normal, and liver biopsy showed only bile stasis. A T-tube was placed in the common bile duct, and the jaundice subsequently cleared. Clamping of the T-tube on two occasions resulted in prompt recurrence of jaundice. A T-tube cholangiogram showed persistent obstruction with no dye entering the duodenum.

The patient was referred to the Mayo Clinic on November 5 for further evaluation. At physical examination he appeared well and was in no distress. The liver was palpable $1 \mathrm{~cm}$ below the right costal margin, and the T-tube was draining well. Laboratory tests revealed normal values for hemoglobin, leukocytes, fasting true blood sugar, blood urea, prothrombin time, and serum alkaline phosphatase. Serum glutamic oxalacetic transaminase was slightly elevated at $2.96 \mu$ moles per hour (normal <1.43), and total serum bilirubin was $1.2 \mathrm{mg}$ per $100 \mathrm{ml}$, of which $0.7 \mathrm{mg}$ was direct-reacting pigment (Powell method). A 72-hour stool collection contained a total of $4.4 \mathrm{mg}$ of urobilinogen. Complete obstruction of the distal common bile duct was demonstrated by T-tube cholangiography.

Exploration on November 12 revealed a $2-\mathrm{cm}$ scirrhous adenocarcinoma, grade 2 , in the head of the pancreas with invasion and obstruction of the distal common bile duct, and a Whipple procedure was carried out. There was no gross hepatic metastasis, and a single local lymph node was involved with carcinoma.

At the time that this patient was admitted to the hospital we were engaged in a study of BSP transport and metabolism in hepatic disorders in man (4), investigating the $\mathrm{Tm}$ and the relative storage capacity (S) for BSP by the constant-infusion technic of Wheeler, Meltzer, and Bradley (2). These parameters were measured in this patient on two occasions 3 days apart. Each time, bile was collected via the T-tube, and in one of the two 
experimental periods urine was collected from a urethral catheter during the course of the continuous infusion.

Studies were carried out after a 12-hour fast, with the patient reclining comfortably on a bed. After control specimens of bile, urine, and blood had been collected, BSP was infused intravenously for 1 hour at a carefully controlled constant drop rate of about $0.15 \mathrm{mg}$ per minute per $\mathrm{kg}$ body weight. The infusion rate was changed to approximately $0.045 \mathrm{mg}$ per minute per $\mathrm{kg}$ during the second hour and 0.09 during the third. The theory and details of the constant-infusion technic for determination of theoretical $\mathrm{Tm}(2)$ are described in the accompanying manuscript (4).

Bile was collected continuously throughout the study in successive separate graduated test tubes at intervals of 10 or 15 minutes by gravity drainage from the T-tube. Urine was collected continuously in separate receptacles every 30 minutes.

The BSP concentration and the proportion of BSP conjugates (5) were determined for each measured sample of serum, bile, or urine.

Colorimetrically measured BSP excretion in bile was compared with the theoretical Tm determined simultaneously from observation of concentrations in peripheral serum obtained during the infusions at each constant rate.

After completion of the third hour of the first study, bile was collected at half-hour intervals for an additional 3 hours without further infusion of BSP. In the second study, after completion of the third hour, a fourth constant infusion of BSP was administered at the rate of the theoretical $\mathrm{Tm}(2.9 \mathrm{mg}$ per minute). During this fourth infusion period at the Tm rate, an additional $200 \mathrm{mg}$ of $\mathrm{BSP}$ was rapidly injected intravenously. Bile, serum, and urine specimens were obtained and analyzed as described above.

\section{Results}

Concentrations in bile and in serum. Figure 1 illustrates the estimation of theoretical $\mathrm{Tm}$ and $\mathrm{S}$ for BSP and the S obtained during the second study in this patient. (The results of both studies were virtually identical; therefore, only those from the second will be reported in full detail.) Plasma concentration changed in linear fashion with respect to time during the latter half of each infusion period (Figure $1 a$ ). Figure $1 b$ illustrates the estimation of $\operatorname{Tm}$ (where $\Delta \mathrm{p} / \Delta \mathrm{t}=0$ ). The hepatic removal rate was greater than the excretory rate during the periods of increasing plasma concentration, indicating accumulation of BSP in the liver. When the plasma concentration was falling (second infusion period), the removal rate was less than the excretory rate, indicating net depletion of stored BSP (Figure $1 c$ ).
In Figure 2 the colorimetrically measured BSP excreted in the bile during different rates of continuous intravenous infusion of the dye is compared with the theoretical Tm determined simultaneously. BSP first appeared in the bile between 15 and 30 minutes after the start of the initial infusion. Probably after 30 minutes and certainly by 40 minutes, a maximal rate for biliary excretion of BSP had been attained. The Tm for BSP determined colorimetrically ranged from 1.6 to $3.1 \mathrm{mg}$ per minute with a mean of $2.4 \pm 0.5$ (SD) during the continuous 3-hour infusion of the dye. Thus the average colorimetrically determined $\mathrm{Tm}$ was 89.7 and $82.8 \%$ of the theoretical $\mathrm{Tm}$ in the first and second studies, respectively. That both theoretical and colorimetrically determined Tm's for BSP are well below the normal value for the theoretical measurement (Table I) emphasizes that the patient studied cannot be considered as normal with respect to hepatobiliary function.

The range of $\mathrm{BSP}$ concentrations encountered in bile during the continuous infusions was from 267 to $1,820 \mathrm{mg}$ per $100 \mathrm{ml}$, and the bile flow rate varied from 0.10 to $0.42 \mathrm{ml}$ per minute. Figure 3 shows the variations in bile flow rate and BSP concentration in bile during the different rates of continuous intravenous infusion of BSP. The higher rates of bile flow appeared to coincide with the lower BSP concentrations and the lower rates of bile flow with the higher BSP concentrations, regardless of the rates of infusion. Accordingly, a correlation regression analysis was made of bile BSP concentration on bile flow rate. Figure 4 shows the results of this analysis. There was a significant negative regression of bile BSP con-

TABLE I

Relationship between colorimetric and theoretical values of maximal biliary excretion (Tm) of BSP

\begin{tabular}{ccccc}
\hline & \multicolumn{3}{c}{$\mathrm{Tm}$} & \multicolumn{3}{c}{$\begin{array}{c}\text { Percent- } \\
\text { age, colori- } \\
\text { metric } \\
\text { of theo- } \\
\text { retical }\end{array}$} & $\mathrm{S}$ \\
\cline { 2 - 5 } Sources & $\begin{array}{c}\text { Colori- } \\
\text { metric }\end{array}$ & Theoretical & & \\
\hline & & $m g / m i n u l e$ & $\%$ & $\mathrm{mg} / \mathrm{mg} / 100 \mathrm{ml}$ \\
$\begin{array}{c}\text { Normal } \\
\text { group* }\end{array}$ & & $8.2 \pm 2.9$ & & $60.6 \pm 27.7$ \\
$\begin{array}{c}\text { First } \\
\text { study } \\
\text { Second } \\
\text { study }\end{array}$ & 2.6 & 2.9 & 89.7 & 20.3 \\
& 2.4 & 2.7 & 82.8 & 26.8 \\
\hline
\end{tabular}

* Mean for 19 subjects $\pm 2.1 \mathrm{SD}$ (95\% confidence limits) (4). 
centration on bile flow rate with a correlation coefficient of $-0.7963(\mathrm{p}<0.01)$. The linear regression equation was $y=19.1-3.437(x)$.

Metabolized BSP in bile and in serum. Three different compounds were demonstrated chromatographically in all bile samples. One (arbitrarily designated BSP I) had an $R_{\mathbf{f}}$ of about 0.50 and was identical in chromatographic characteristics

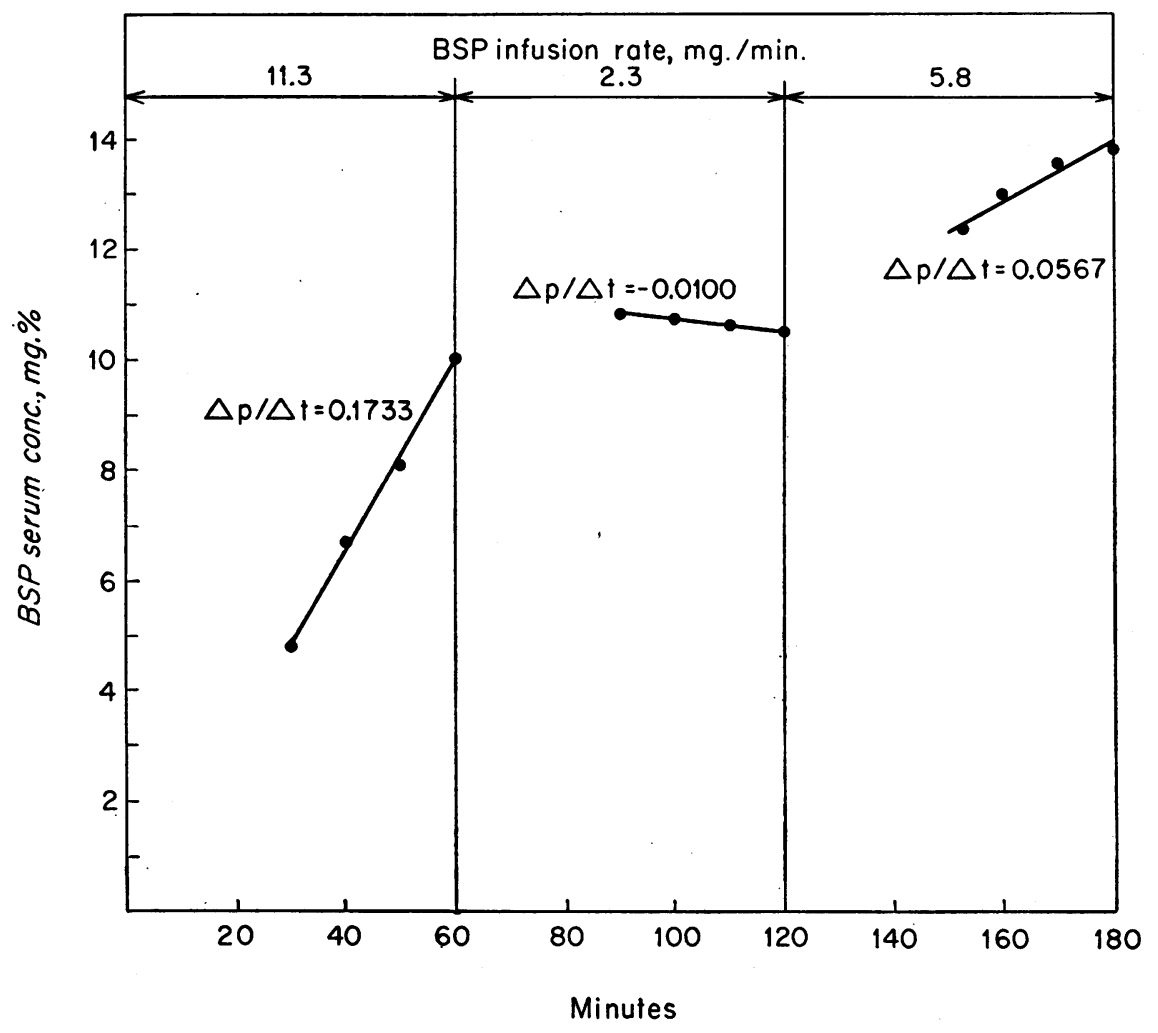

$a$

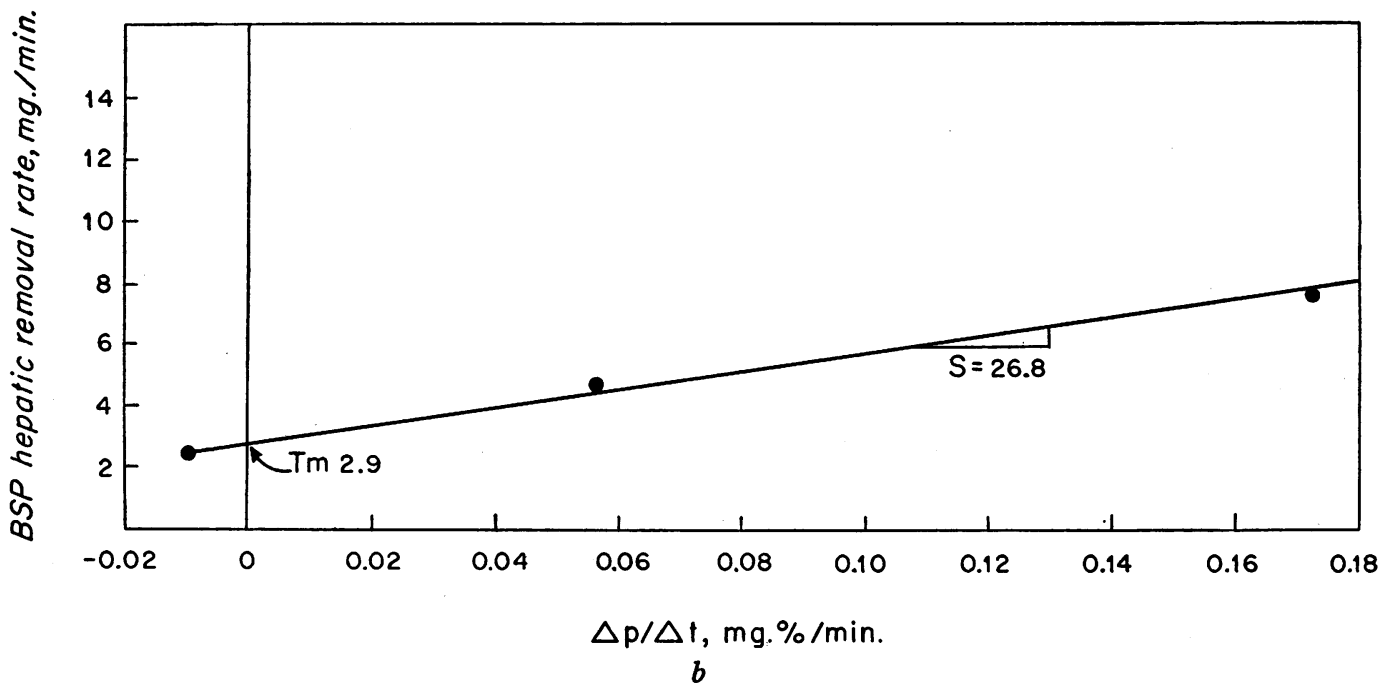

Fig. 1.-Continued on facing page. 


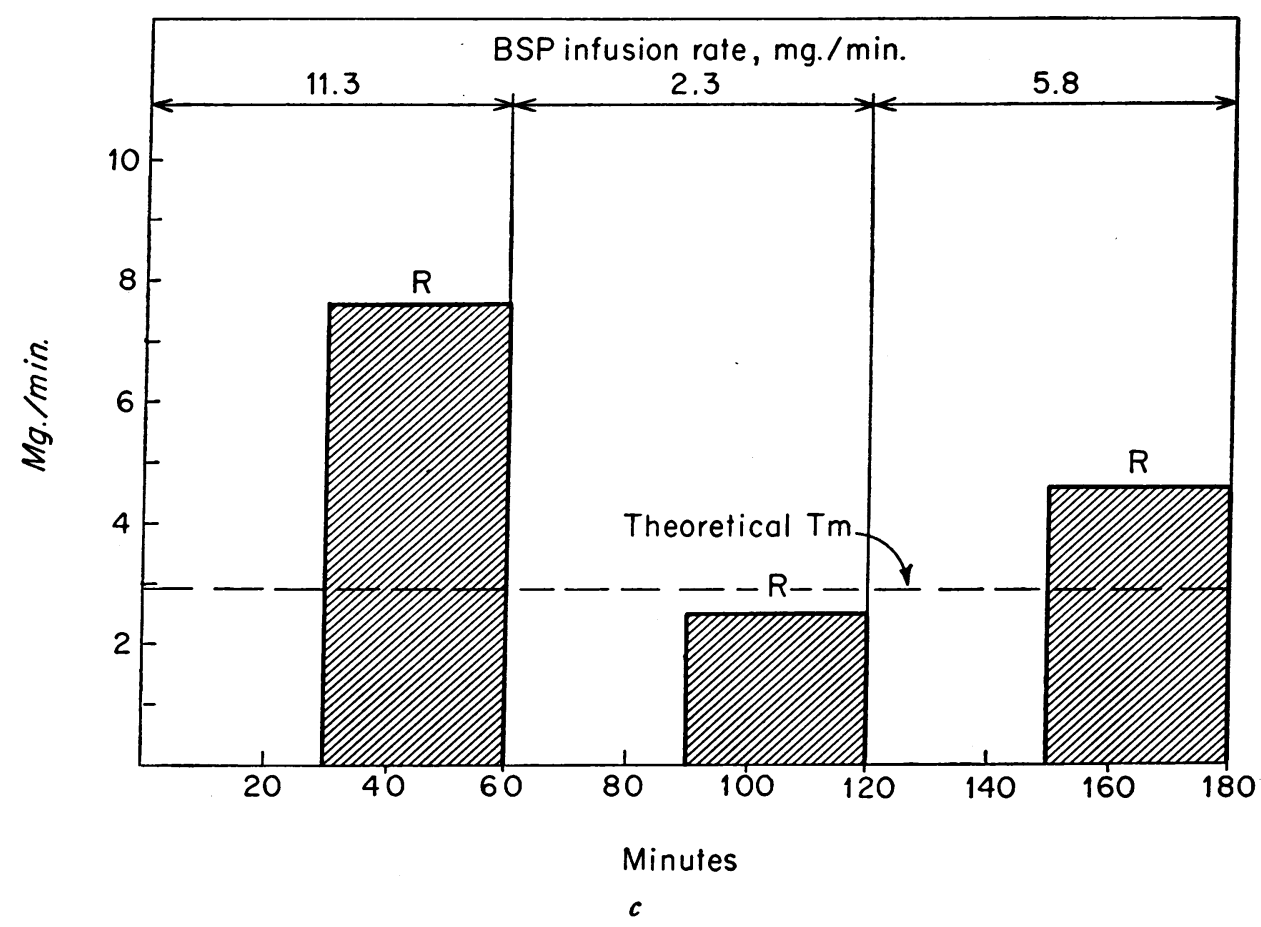

Fig. 1. Estimation of theoretical TM and $S$ for BSP and the $S$ obtained in the SECOND STUDY. a) Change in serum concentration with time $(\Delta \mathrm{p} / \Delta \mathrm{t})$ during second half hour of each indicated infusion period. b) Determination of theoretical $\mathrm{Tm}$ and $\mathrm{S}$ by plotting $\mathrm{R}$ (hepatic removal rate) against corresponding values of $\Delta \mathrm{p} / \Delta \mathrm{t}$ for each infusion period. Tm equals $\mathrm{R}$ when $\Delta \mathrm{p} / \Delta \mathrm{t}=0$; $\mathrm{S}$ is slope of line. Plasma volume was $2,153 \mathrm{ml} . c$ ) Theoretical hepatic removal rates (shaded areas) compared with theoretical $\mathrm{Tm}$ during each infusion period.

with commercially available BSP that had been dissolved in control bile or serum. The two other compounds had $R_{f}$ values of about 0.40 (BSP II) and 0.30 (BSP III), although occasionally an additional compound with an $R_{f}$ of about 0.20 (BSP IV) was found.

Eluted BSP III and BSP IV were combined as "BSP III" for determinations in these experiments. In 15 determinations, $91.0 \pm 4.1 \%$ and $85.2 \pm 3.6 \%$ of BSP added in known amounts to serum or bile, respectively, were found in the final colorimetric estimation after paper chromatographic analysis. Duplicate determinations agreed within $8 \%$.

During the course of the continuous intravenous infusions, BSP and its metabolites were excreted in the bile in nearly constant proportions (Table II). While the biliary excretion of BSP was maximal, the proportion of serum BSP in metabolized form increased as a function of time, in- dependently of the rate of infusion or the serum concentration of BSP attained. The linear regression equation for serum BSP conjugates on time was $y=-7.63+0.3400 x$, and the $\mathrm{r}$ was highly significant $(\mathrm{p}<0.001)$.

Constancy of Tm. Urinary excretion of BSP during the 3 hours of continuous infusion remained relatively constant, ranging from 0.4 to $0.5 \mathrm{mg}$ per minute and amounting to about $7 \%$ of the total BSP infused. Table III shows that 90.9 and $93.0 \%$ of the infused BSP could be accounted for during the first and second studies, respectively. Uptake of BSP by extrahepatic tissue was not considered.

After completion of the third infusion period in the first study, bile collected for an additional 3 hours, without further infusion of BSP, still contained BSP excreted at the same maximal rate (Figure $5 a$ ). The serum BSP concentration 90 minutes after infusion had ended was $4.5 \mathrm{mg}$ 


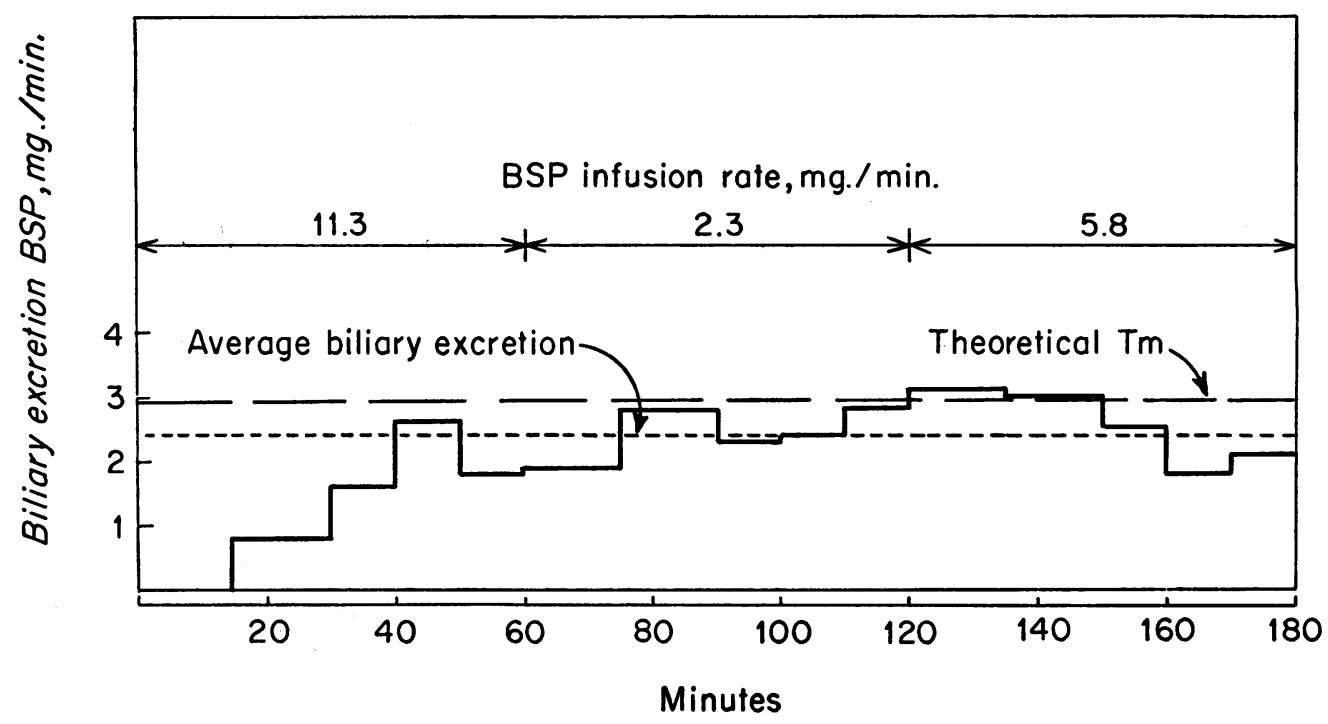

Fig. 2. EXCRETION OF BSP IN BILE DURING DIFFERENT RATES OF INTRAVENOUS INFUSION OF THE DYE. Average excretion colorimetrically determined (2.4 mg per minute) is $82.8 \%$ of simultaneously estimated theoretical $\mathrm{Tm}$ (2.9 $\mathrm{mg}$ per minute).

per $100 \mathrm{ml}$, or about one-third of the serum BSP mined during the three postinfusion hours or later, level at the end of the 3-hour infusion. Since it was not possible to characterize the decrement other BSP serum concentrations were not deter- in serum BSP or to estimate the level of serum

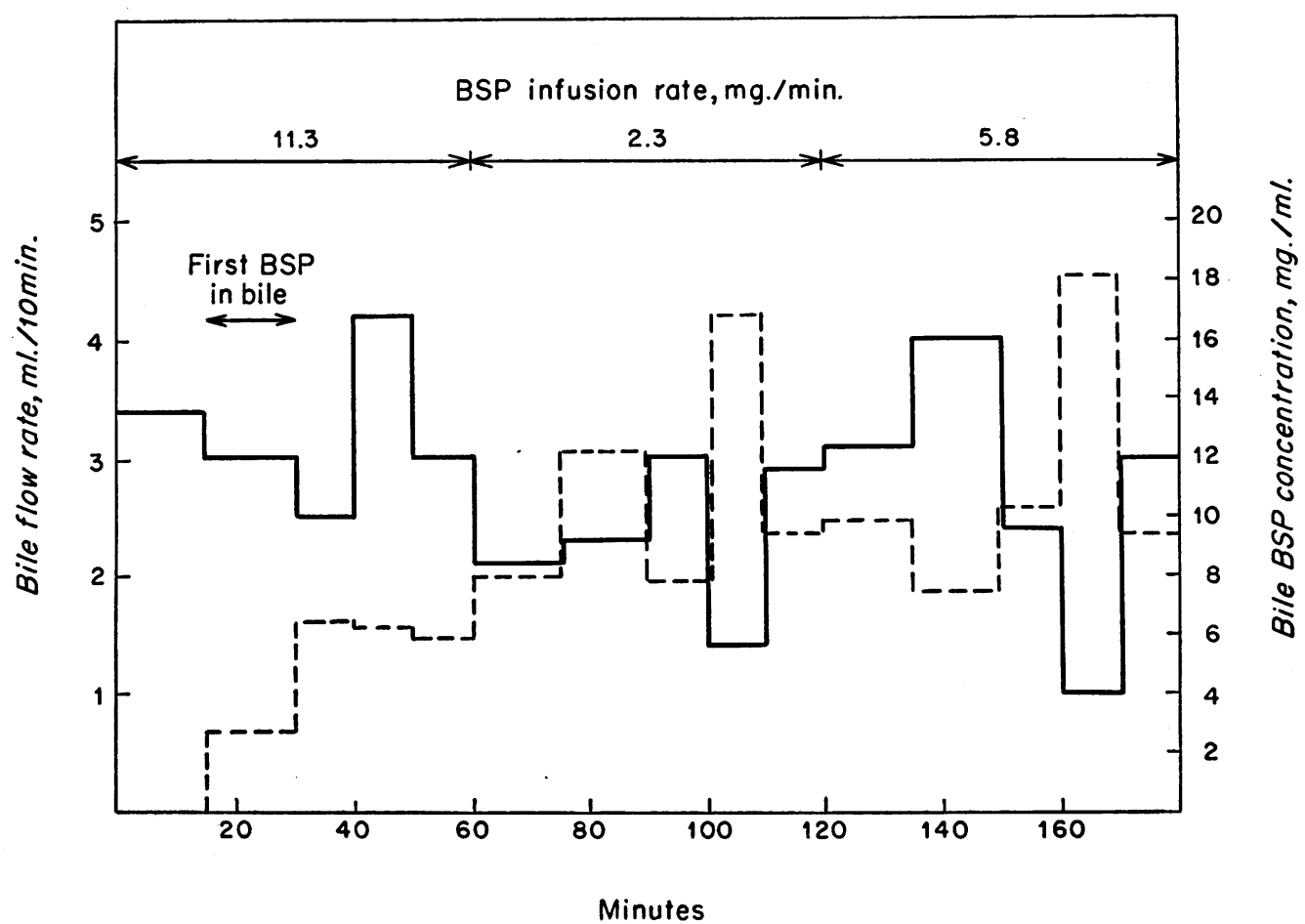

Fig. 3. Bile flow RAte (-) ANd BSP concentration in BILE (-- - ) DURing different RATES OF CONTINUOUS INTRAVENOUS INFUSION OF BSP. Relationship appears to be reciprocal. 


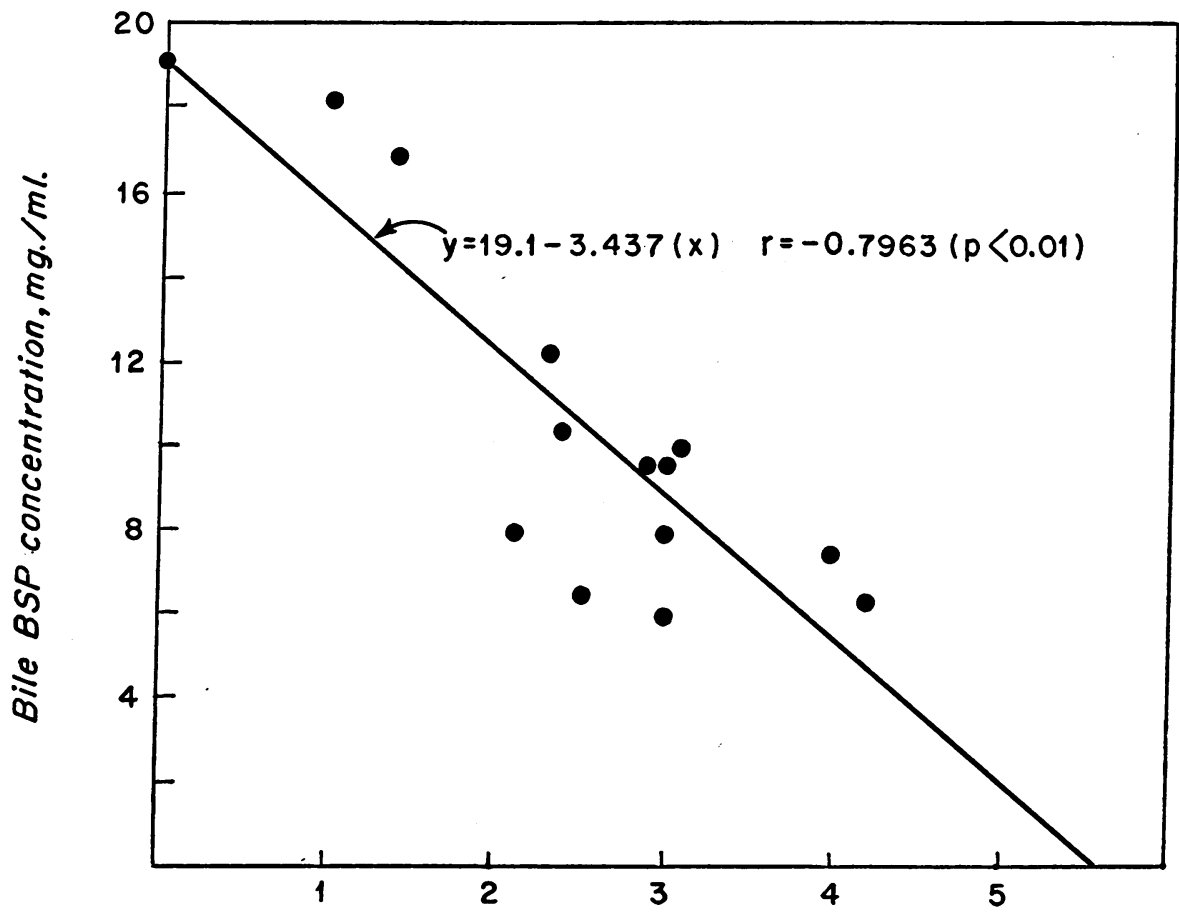

Bile flow, $\mathrm{ml} . / 10 \mathrm{~min}$.

Fig. 4. Regression OF BILE BSP CONCENTRATION ON BILE fLOW RATE FOR CONSECUTIVE SPECIMENS OF BILE OBTAINED DURING CONTINUOUS INTRAVENOUS INFUSION OF BSP. Linear regression equation $(y=a+b x), \mathrm{r}$, and $\mathrm{p}$ of chance occurrence of such a relationship are indicated on graph.

BSP at which the Tm might cease to be maintained. The maintenance of the $\mathrm{Tm}$ while the plasma level is falling likely represents, in part at least, a net release to the bile of stored BSP.
After completion of the third hour of the second study, a fourth infusion of BSP at 2.9 $\mathrm{mg}$ per minute was started (Figure $5 b$ ). At this rate of infusion (theoretical $\mathrm{Tm}$ ) the serum BSP

TABLE II

BSP metabolites in bile and in serum during consecutive hourly intravenous infusions at different rates

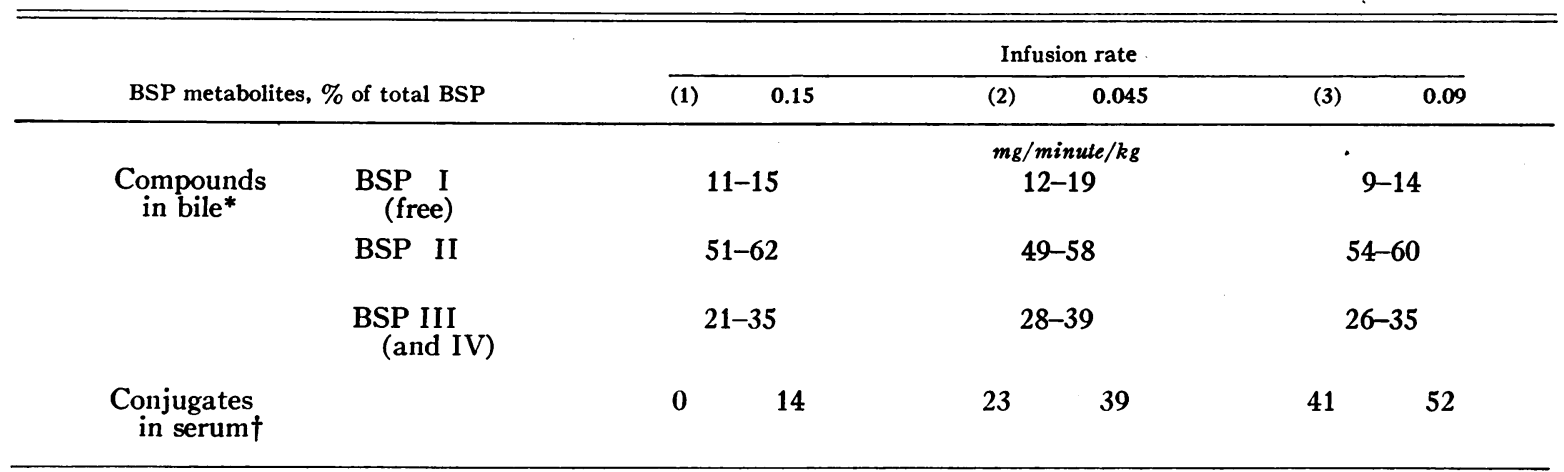

* Range of values of four specimens obtained during each infusion period.

$\dagger$ Each value for 30 -minute interval is mean of two determinations. 


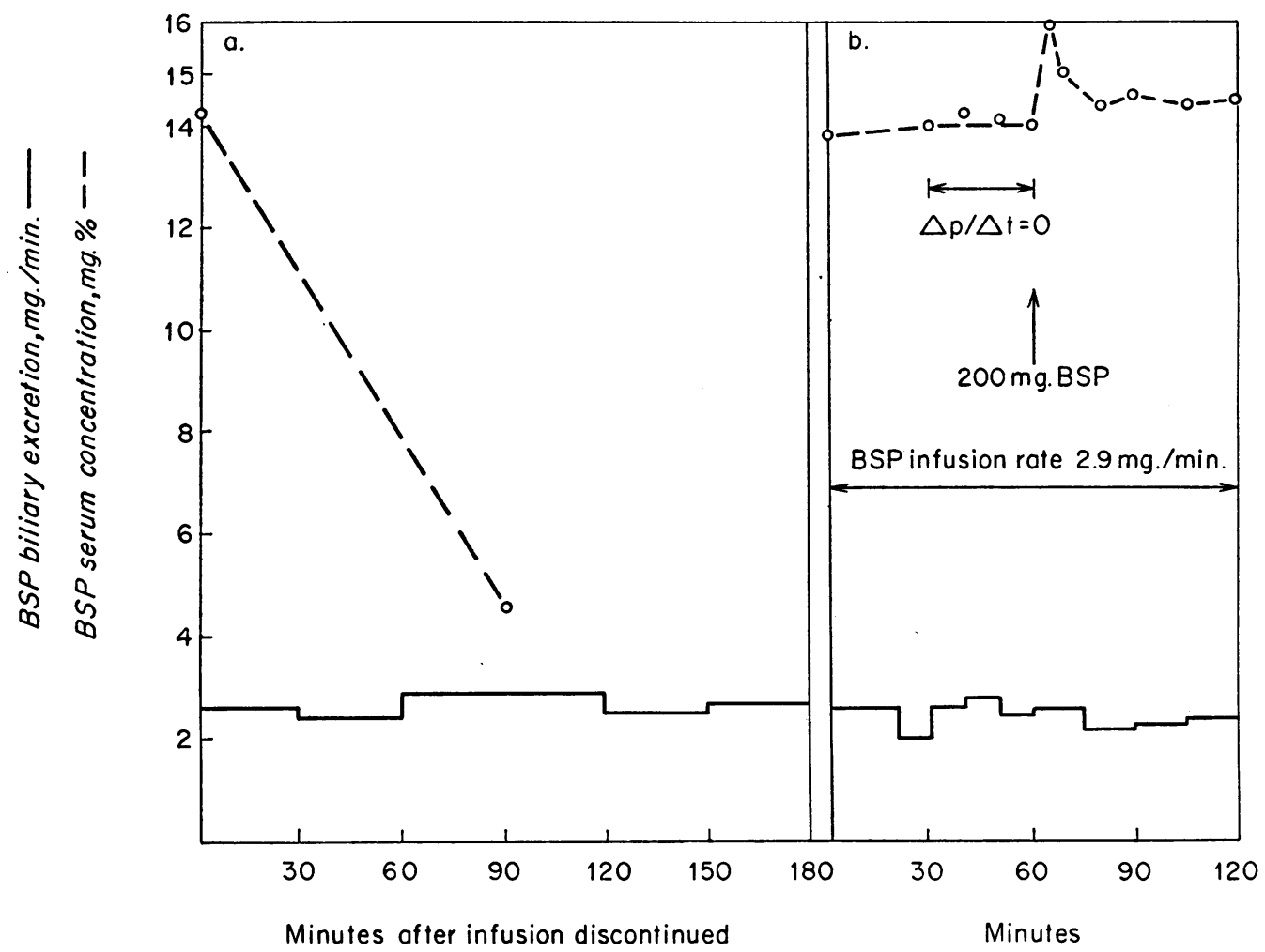

Fig. 5. EFFECT OF SUDDEN INCREMENT OR DECREMENT OF SERUM ON TM. a) BSP serum concentration determined at end of 3-hour intravenous infusion and 90 minutes after end. Biliary excretion of BSP remained virtually constant for 3 hours after infusion of BSP was stopped. b) BSP serum concentration and biliary excretion of BSP determined during continuous infusion at rate equal to theoretical $\mathrm{Tm}$. Between 30 and 60 minutes, $\Delta \mathrm{p} / \Delta \mathrm{t}=0$. At 60 minutes, additional $200 \mathrm{mg}$ of BSP was injected rapidly intravenously without producing change in biliary BSP excretion.

remained at a constant level, indicating that, indeed, BSP was being administered at the same rate at which it was being excreted in the bile. When an additional $200 \mathrm{mg}$ of BSP was rapidly injected intravenously during this continuous infusion, no change in the rate of biliary excretion of BSP occurred. That the serum concentration rose and within 20 minutes fell almost to the level present before the sudden increment in serum BSP probably represents net uptake of BSP into the storage compartment. There was no significant change in urinary excretion of BSP during

TABLE III

Estimated recovery of infused BSP

\begin{tabular}{|c|c|c|c|c|c|c|c|}
\hline \multirow[b]{2}{*}{ Study } & \multirow[b]{2}{*}{$\begin{array}{l}\text { Infused } \\
3 \text { hours }\end{array}$} & \multirow[b]{2}{*}{$\begin{array}{l}\text { Biliary } \\
\text { output }\end{array}$} & \multirow[b]{2}{*}{$\begin{array}{l}\text { Urinary } \\
\text { output }\end{array}$} & \multirow{2}{*}{$\begin{array}{l}\text { Calculated } \\
\text { in plasma, } \\
\text { end } 3 \\
\text { hours }\end{array}$} & \multirow{2}{*}{$\begin{array}{l}\text { Calculated } \\
\text { in storage, } \\
\text { theoretical, } \\
\text { end } 3 \\
\text { hours }\end{array}$} & \multicolumn{2}{|c|}{ Accounted for } \\
\hline & & & & & & Amount & Per cent \\
\hline First & $\begin{array}{c}m g \\
1,206\end{array}$ & $\begin{array}{c}m g \\
936 \\
\text { (6-hour) }\end{array}$ & $\begin{array}{c}m g \\
160 \\
\text { (6-hour, } \\
\text { presumed) }\end{array}$ & $m g$ & $m g$ & $\begin{array}{c}m g \\
1,096\end{array}$ & $\begin{array}{c}\% \\
90.9\end{array}$ \\
\hline Second & 1,164 & $\begin{array}{c}432 \\
\text { (3-hour) }\end{array}$ & $\begin{array}{c}80 \\
\text { (3-hour) }\end{array}$ & 248 & 322 & 1,082 & 93.0 \\
\hline
\end{tabular}


this time, and it is unlikely that extrahepatic removal of BSP was responsible for the observed decrease in serum BSP (2).

\section{Discussion}

The inherent limitations of attempts to obtain complete collections of bile in man are well appreciated. In the patient studied, however, liver biopsy and conventional tests of hepatic function gave little indication of impairment, but complete obstruction of the common bile duct was proved. The presence of a $\mathrm{T}$-tube above the obstruction permitted a nearly complete collection of the biliary drainage. The "recoveries" of BSP in bile and the virtual absence of fecal urobilinogen attest to the adequacy of collection and minimize the significance of possible accessory-duct drainage in this subject.

Obviously, the recorded observations represent abnormal rather than normal physiologic phenomena. The values obtained directly and indirectly for $\mathrm{Tm}$ (as well as indirectly for $\mathrm{S}$ ) were decidedly below the normal range of values we have estimated with the constant infusion technic (4). The deleterious effects of common-duct obstruction on liver function, particularly at the ultramicroscopic (6) and enzymatic (7) levels, have been well established. Also, diversion of bile to the exterior results in alterations of the normal physiology (8). However, in these experiments a Tm of BSP was found which-once established-held constant despite different rates of infusion and regardless of increment or decrement in the plasma concentration of BSP. That the $\mathrm{Tm}$ was maintained in the face of changing rates of bile flow suggests a rate rather than a concentration maximum.

The indirect measurement of $\mathrm{Tm}$ from observations on peripheral plasma concentrations during different rates of infusion resulted in values only slightly greater than those simultaneously obtained by spectrophotometric determinations of BSP in bile. This indicated that, despite mild impairment of liver function and the fact that some extrahepatic removal is known to occur (9), biliary excretion was the major mechanism for BSP elimination. Since the theoretical $\mathrm{Tm}$ includes both biliary and urinary excretion, the colorimetric $\mathrm{Tm}$ is even closer to the actual biliary excretory $\mathrm{Tm}$ than indicated here. It has been shown that a metabolic transformation of most BSP administered intravenously occurs in the liver (10) and that this conjugation occurs primarily with glutathione (11). Since the BSP conjugates in bile may have a lower molar extinction coefficient than BSP itself, the biliary excretory rate may have been, if anything, underestimated by the colorimetric technic (12).

Whether there are separate Tm's for free BSP and BSP conjugates has not been determined. BSP and its conjugates may, because of structural differences, utilize independent transport mechanisms (13). Unfortunately, a study of the enterohepatic circulation of BSP (14) was not accomplished in this patient. Since bile was diverted to the exterior, the influence of this system on biliary excretion has been excluded from these experiments. However, the enterohepatic circulation of BSP seems to be of rather limited magnitude (2).

Brauer and Pessotti (15) found in the dog that although BSP concentration in bile reached a maximum of about $1,000 \mathrm{mg}$ per $100 \mathrm{ml}$ during the steady state, BSP excretory rates fluctuated by 15 to $20 \%$ because of variation in biliary flow. The finding of a rate maximum rather than a concentration maximum for biliary excretion of BSP in man agrees with the report of Wheeler and collaborators (2) from their study in dogs. Also, the range of concentrations of BSP in bile reported herein was comparable to that which they found.

\section{Summary}

Experiments utilizing continuous infusion technics have been conducted on an individual who afforded an opportunity for physiologic study of biliary excretion. They are presented as direct evidence supporting the concept of a transport rate maximum ( $\mathrm{Tm}$ ) for biliary excretion of sulfobromophthalein sodium (BSP) in man.

The $\mathrm{Tm}$ for BSP determined colorimetrically in bile was $86 \%$ of the Tm estimated from serum BSP concentrations during continuous infusion of the dye, with $92 \%$ of infused BSP recovered or accounted for.

Although the proportions of BSP compounds in the bile during the continuous intravenous infusion at different rates were constant, the per- 
centage of metabolized BSP in the serum increased with time. Whether there are separate Tm's for free BSP and BSP conjugates has not been determined.

Infusion of BSP at the theoretical Tm resulted in a steady state of serum BSP concentration, whereas colorimetrically determined maximal biliary excretion remained constant. The constant Tm was unaltered by sudden increase of serum $\mathrm{BSP}$, indicating accumulation of BSP in the liver, and was likewise unchanged by sudden decrease of serum BSP, indicating depletion of stored dye.

\section{References}

1. Wheeler, H. O., R. M. Epstein, R. R. Robinson, and E. S. Snell. Hepatic storage and excretion of sulfobromophthalein sodium in the dog. J. clin. Invest. 1960, 39, 236.

2. Wheeler, H. O., J. I. Meltzer, and S. E. Bradley. Biliary transport and hepatic storage of sulfobromophthalein sodium in the unanesthetized dog, in normal man, and in patients with hepatic disease. J. clin. Invest. 1960, 39, 1131.

3. Scherb, J., M. Kirschner, and I. Arias. Studies of hepatic excretory function: the effect of $17 \alpha-$ ethyl-19-nortestosterone on sulfobromophthalein sodium (BSP) metabolism in man. J. clin. Invest. 1963, 42, 404.

4. Schoenfield, L. J., W. T. Foulk, and H. R. Butt. Studies of sulfobromophthalein sodium (BSP) metabolism in man. I. In normal subjects and patients with hepatic disease. J. clin. Invest. 1964, 43, 1409.

5. Meltzer, J. I., H. O. Wheeler, and W. I. Cranston. Metabolism of sulfobromophthalein sodium (BSP) in dog and man. Proc. Soc. exp. Biol. (N. Y.) 1959, 100, 174.

6. Schaffner, F., and H. Popper. Electron microscopic study of human cholestasis. Proc. Soc. exp. Biol. (N. Y.) 1959, 101, 777.

7. Schoenfield, L. J., J. L. Bollman, and H. N. Hoffman II. Sulfate and glucuronide conjugates of bilirubin in experimental liver injury. J. clin. Invest. 1962, $41,133$.

8. Sperber, I. The biliary excretion and choleretic effect of some phenolsulphonephthaleins (abstract). Acta physiol. scand. 1958, 42 (suppl. 145), 129.

9. Rosenau, W., J. V. Carbone, and G. M. Grodsky. Metabolism of sulfobromophthalein in hepatectomized and hepatectomized-nephrectomized dog. Proc. Soc. exp. Biol. (N. Y.) 1959, 102, 131.

10. Brauer, R. W., R. L. Pessotti, and J. S. Krebs. The distribution and excretion of $\mathrm{S}^{35}$-labeled sulfobromophthalein-sodium administered to dogs by continuous infusion. J. clin. Invest. 1955, 34, 35.

11. Grodsky, G. M., J. V. Carbone, and R. Fanska. Identification of metabolites of sulfobromophthalein. J. clin. Invest. 1959, 38, 1981.

12. Krebs, J. S., and R. W. Brauer. Metabolism of sulfobromophthalein sodium (BSP) in the rat. Amer. J. Physiol. 1958, 194, 37.

13. Bradley, S. E. The circulation and the liver. Gastroenterology 1963, 44, 403.

14. Lorber, S. H., M. J. Oppenheimer, H. Shay, P. Lynch, and H. Siplet. Enterohepatic circulation of bromsulphalein: intraduodenal, intraportal and intravenous dye administration in dogs. Amer. J. Physiol. 1953, 173, 259.

15. Brauer, R. W., and R. L. Pessotti. Hepatic uptake and biliary excretion of bromsulphthalein in the dog. Amer. J. Physiol. 1950, 162, 565. 